\title{
SWENSON'S OPERATION FOR TREATMENT Of HIRSCHSPRUNG'S DISEASE, SHORT AND LONG TERM OUTCOME.
}

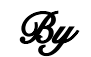 \\ Ahmad Nabih Anwar EL Ghawalby \\ From \\ Gasrointestinal Surgical Center, Department of Surgery \\ Mansoura Faculty of Medicine, Mansora University
}

\begin{abstract}
Background / Aim : Many definitive operations exist for Hirshsprung's disease, each of these operations is highly effective in the relief of functional obstruction, on the other hand each operation has some complications. The aim of this study is to evaluate Swenson's operation as a method for treatment of Hirschsprung's disease and assessment of short and long term outcome.
\end{abstract}

\section{Methodology :}

Forty patients under went Swenson's operation over 4 years, they were 25 males and 15 females with mean age 6.64 years (range 6months- 12 years). Preoperative history and clinical assessment, laboratory, radiologically and manome- try were done in all cases. Postoperative evaluation of outcome was studied.

\section{Results :}

No mortality in our cases .Soiling occured in 2 cases, minor incontinence in 7 cases (17.5\%) and major incontinence in 5 cases (12.5\%), enterocolitis in 5 cases $(12.5 \%)$ .constipation in 4 cases (10\%).

Leakage associated with wound and pelvic collection in 2 cases (5\%) and was treated with antibiotics and leaving the drains for 6 to 8 days. One case developed rectovaginal fistula, one case of anal stricture, one case of recurrent Hirschsprung s' disease. On follow up these symptoms improved through along the first and second year post- operatively.

MANSOURA MEDICAL JOURNAL 


\section{SWENSON'S OPERATION FOR TREATMENT etc...}

\section{Conclusion:}

Swenson's operation is the original curative pull- through procedure especially if precisely performed. However, it has some complications. Anal stricture may complicate ischaemia of the pulled through segment. Enterocolitis remains a serious complication. Incontinence has a relatively high incidence but with significant improvement with time.

Key words: Hirschsprung's disease, Swenson 's operation.

\section{INTRODUCSTION}

Hirschsprung's disease is a congenital disorder characterized by distal aganglionosis, usually involving the rectosigmoid, which results in functional obstruction of the colon (1). Nitric oxide which is a neurotransmitter in the noncholinergic inhibitory nerves,is absent in the ganglionic region and the internal anal sphincter causing spasticity of both (2). The transitional zone lies in the rectum or sigmoid colon in $75 \%$ $80 \%$, and reaching the splenic flexure in $13.5 \%-15 \%$, while total colonic agangionosis in $0.16 \%-0.4 \%$ of the cases (3).

Many definitive operations exist for Hirschsprung's disease those include Sweenson, Duhamel, Soave, transanal pull- through which is the latest development of treatment (4). Each of these operations is highly effective in the relief of functional obstruction, on the other hand each operation has some complications (5) and so, the long-term outcome and quality of life are not as good as surgens expected (6).

Soiling is common after Swenson's operation possibly due to much excision of the internal anal sphincter (7). Soave's operation entails stripping of the rectal mucosa and endrectal pull-through of the proximal ganglionic colon after resection of the aganglionic segment(5). This technique leaves the aganglionic muscle cuff intact and allows for preservation of the spastic internal anal sphincter that predispose to postoperative constipation and enterocolitis (8). In Duhamel's procedure, the rectum is retained and the normal ganglionic colon is brought down behind the rectum avoiding manipulation of the rectum anteriorly (9). So the new rectum is composed of normal colon posteriorly and inert part anteriorly, 
and peristalsis does not close the lumen and there is no forward movement of the bolus (9).

\section{PATIENTS AND METHODS}

Our study included 40 patients between 2002-2006. They were 25 males and 15 females with mean age $6.64+4.4$ years (6months- 12 years). All patients had been submitted to thorough history and clinical examination as regard delayed passage of meconium, enterocolitis, abdominal distension, loss of weight, and empty rectum. Routine laboratory investigations, barium enema, and rectal muscle biopsy one $\mathrm{cm}$. above the dentate line. Swenson's operation was done as one stage or associated with colostomy. Preoperative colostomy was done due marked abdominal distension or to correct the general condition in 5 patients. Operative colostomy was done if there was colonic distension in 4 patients. Frozen section was done in all patients from the edge of colonic segment anastomosed to the anal canal to confirm the presence of ganglion cells.

Postoperative assessment and follow up for 1-3 years for early complications as leakage, enterocoli- tis, urine retension, incontinence, fistula and constipation. Anal digital examination was done after 3 weeks for anal canal resting and maximum squeeze tone. Barium enema was done if there was stricture or suspicious of recurrence of the disease. Anorectal manometry was done when necessary in the presence of incontinence or constipation to measure the resting and maximum squeeze pressures.

\section{RESULTS}

This study included 40 patients in the period from 2002-2006, all patients were treated by Swenson's operation, they were 25 males and 15 females with mean age $6.64 \% \pm 4.4$ years (6 months- 12 years). Constipation (table 1) was the commonest presentation in all cases(100\%). Abdominal distension in 25 cases $(62.5 \%)$ with recurrent attacks of intestinal obstruction in 10 cases (25 $\%)$. Delayed passage of meconium in 15 cases (35\%) and enterocolitis in 2 cases (5\%). Barium enema was diagnostic in all cases. Rectal muscle biopsy was aganglionic in all cases (100\%)(table1). The mean operative time was $125.3 \pm 44.22 \mathrm{~min}$ utes (90-140 mintues). Oral feeding started 2-4 days. Hospital stay was 
$5.1 \pm 1.9$ days (4-10 days).

Early postoperative complications (Table2) was wound infection in 2 cases $(5 \%)$ and controlled by antibiotics and wound care, urine retention in one case $(2.5 \%)$ and managed by a catheter for one week.Minor incontinence in 5 cases $(12.5 \%)$, soiling in 2 cases $(5 \%)$ and major incontinence in 8 cases $(20 \%)$. Enterocolitis in 5 cases $(12.5 \%)$ and respond to metronidazole in pediatric dose for one week. Constipation in 4 cases $(10 \%)$ that responded to the transient use of laxatives, anastomotic leakage in 2 cases $(5 \%)$ and treated by diverting colostomy for 10 days in the hospital and completed the treatment in the outpatient clinic for another 5 to 10 days as the leakage was minor. These fistulae stopped within 2 and 3 weeks. One case developed rectovaginal fistula that was treated by colostomy followed by perineal repair after 4 months, then closure of the colostomy 3 weeks later. late complications were anastomotic stricture in one case $(2.5 \%)$ which was treated with repeated anal dilatation,one case $(2.5 \%)$ developed recurrence of the disease and treated by re-Swenson's operation with great response, minor incontinence in 4 cases $(10 \%)$ and major incontinence in 2 cases( $5 \%$ ) (table 3).

Follow up of the incontinent children for one year, the number decreased from 6 cases ( 4 minor and 2 major) to 4 cases (3minor and one major)which remain the same through 2 and 3 years. Anorectal manometry was done for 6 cases of incontinence, (table 5). The mean resting pressure was 58. $1 \pm 15.1$ $\mathrm{MmHg}$ in normal cases while it was significantly lower in the incontinent cases with mean $42.9 \pm 16.2 \mathrm{mmHg}$. Also the mean maximum squeeze pressure was $87.6 \pm 28.7$ in the incontinent cases which was significantly lower than normal cases with mean $107.7 \pm 28.5$ (table 4, table 5). 
Table(1) Preoperative data (no. 40)

\begin{tabular}{|l|l|l|}
\hline Findings & No & $\%$ \\
\hline Delayed passage of meconium & 15 & 37.5 \\
\hline Constipation & 40 & 100 \\
\hline Recurrent intestinal obstruction & 10 & 25 \\
\hline Enterocolitis & 2 & 5 \\
\hline Abdominal distension & 25 & 62.5 \\
\hline Diagnostic barium enema & 40 & 100 \\
\hline Rectal muscle biopsy( aganglionic segment) & 40 & 100 \\
\hline
\end{tabular}

Table (2) Early postoperative complications :

\begin{tabular}{|l|l|l|}
\hline Complication & No. & \% \\
\hline Wound infection & 2 & 5 \\
\hline Urine retension & 1 & 2.5 \\
\hline Minor incontinence & 7 & 17.5 \\
\hline Major incontinence & 5 & 12.5 \\
\hline Enterocolitis & 5 & 12.5 \\
\hline Constipation & 4 & 10 \\
\hline Leakage & 2 & 5 \\
\hline Fistula & 1 & 2.5 \\
\hline
\end{tabular}


Table(3) Patients morbidity

\begin{tabular}{|l|l|l|}
\hline Causes & NO. & \% \\
\hline Fistula (rectovaginal ) & 1 & 2.5 \\
\hline Enterocolitis & 5 & 12.5 \\
\hline Minor incontinence & 4 & 10 \\
\hline Major incontinence & 2 & 5 \\
\hline Recurrent constipation & 4 & 10 \\
\hline Recurrence of the disease & 1 & 2.5 \\
\hline Stricture & 1 & 2.5 \\
\hline
\end{tabular}

Table (4) Long term follow up of morbid cases :

\begin{tabular}{|c|l|l|l|l|l|l|}
\hline & \multicolumn{2}{|l|}{ 1 Years } & \multicolumn{2}{l|}{ 2Years } & \multicolumn{2}{l|}{ 3Years } \\
\hline & NO. & $\%$ & NO. & $\%$ & NO. & $\%$ \\
\hline Enterocolitis & 5 & 12.5 & 4 & 10 & 3 & 7.5 \\
\hline Incontinence & 6 & 15 & 4 & 10 & 4 & 10 \\
\hline $\begin{array}{c}\text { Minor } \\
\text { incontinence }\end{array}$ & 4 & 10 & 3 & 7.5 & 3 & 7.5 \\
\hline $\begin{array}{c}\text { Major } \\
\text { incontinence }\end{array}$ & 2 & 5 & 1 & 2.5 & 1 & 2.5 \\
\hline Constipation & 4 & 10 & 3 & 7.5 & 2 & 5 \\
\hline
\end{tabular}

Table (5) Anorectal manometry in continent and incontinent cases

\begin{tabular}{|l|l|l|l|}
\hline & Continent & incontinent & P-Value \\
\hline & $($ No= 6) & $($ No= 6) & \\
\hline $\begin{array}{l}\text { Resting pressure } \\
\text { pressure }\end{array}$ & $58.1 \pm 15.1$ & $42.9 \pm 16.2$ & 0.01 \\
\hline
\end{tabular}

Vol. 43, No. 1 \& 2 Jan. \& April, 2014 
Ahmad Nabih Anwar EL Ghawalby

19

\section{DISCUSSION}

Surgery for Hirschsprung 's disease must satisfy to criteria : The first is eradication of the aganglionic segment and the second is the preservation of fecal incontinence (17). The clinical outcome of affected patients with Hirschsprung's disease has improved deramatically with the development of effective operative procedures. The commonly used procedures include the Soave pullthrough, the Duhamel procedure, the Swenson's procedure, and transanal endorectal pull-through. It is generally thought that there are no significant differences as regard the outcome and long term function of these patients treated by these different procedures. These include a reported increase in the incidence of enterocolitis after Swenson's operation, diarrhea and incontinence after Soave endorectal pull-through and constipation after Dohamal procedure $(19,20)$.

In our study we had no mortality. Mortality rate of $2.4 \%(24), 2.5 \%$ (20), 7.6\% (21) had been reported.Infection as a cause of death had been reported by many authers. The mortality of enterocolitis reaches as high as $30 \%$ (23) and pneumonia or peritonitis was responsible for $18 \%$ of causes of death (15). An increased mortality rate has been noted among those with total colonic aganglionosis or Down syndrome or associated congenital heart disease (13). The incidence of soiling after Swenson's operation was $46.4 \%$ (19) and 50\% (26) due to excessive excision of the internal anal sphincter .

Early surgical complications as wound infection and pelvic abscess occured in 2 cases (5\%) in our series and associated with anastomotic leakage which is similar to that of Sherman(24) who has leakage in $5.6 \%$ and $8.1 \%$ (26). Anastomotic leakage and pelvic abscess nessecitated a diverting colostomy until infection subsides and leakage was controlled. Rectovaginal fistula occurred in one case $(2.5 \%)$ in our series, while it was $1.4 \%(18)$ and $6.2 \%(20)$, in other studies.

Anal stenosis occurred in one case $(2.5 \%)$ in our cases which is better than those of Sherman (24) $7.6 \%$,Kleinhaus (20) $9.5 \%$, and Nixon (21) $14.1 \%$. This complication is probably related to ischaemia in the pull-through segment, and if the operation in complicated by local infec-

MANSOURA MEDICAL JOURNAL 
tion due to anastomotic leakage(16). The surgical options include either an anorectal myotomy or a redo procedure (25).

Enterocolitis is a serious complication of Hirshsprung's disease even after the corrective pull-through procedure. In one series its incidence was $33 \%$, the mean time between the operation and the attack of enterocolitis was 29 months and the longest period was 176 months (12). In our series, the incidence of enterocolitis was $12.5 \%$ in the early postoperative period and $15 \%$ in the first year . Other reported incidences were $22.5 \%(24), 15.6 \%(20)$ and $11.1 \%$ (21). The most prevalent explanation for persistent risk of enterocolitis after corrective procedures is related to the persistently hypertonic anal sphincter associated with the disease causing functional obstruction and inflammation of the colon. Other theories include an alteration in the intestinal mucosa, a deficiency in the intestinal secretory immune system and infection with colostridium difficile (14) and consideration should be given to the use of Vancomycin and metronidazole until culture results are available (11). The role of coexistent intestinal neuronal dysplasia in the proximal colon may be relevant (27). Anorectal manometry revealed a high mean resting pressure among those with postoperative enterocolitis, anal dilatation or even sphincterotomy may prevent recurrence of enterocolitis (23).

Although some reports suggested a good patient satisfaction after surgery, other investigators have found increased incidence of complications and incontinence which resolve with time (23).

Incontinence may be related to decreased neural sensation in the area resulting from the pull-through procedure or to a weakened anal sphincter, making it difficult to expel flatus without passage of liquid stool (22). The number of incontinent cases in our series was 6 cases $(15 \%)$ which decreased to 4 cases $(10 \%)$ in the second and third year postoperatively. Marty (18) had an incidence of $12.6 \%$ and Sherman (24) had an incidence of $4.6 \%$. Postoperative anorectal manometry of incontinent cases in our series revealed a relatively low mean resting pressure $(42.9+16.2 \mathrm{mmHg})$ and maximum squeeze pressure $(87+28.7$ $\mathrm{mmHg}$ ) suggesting that incontinence 
is related to a weakened internal anal sphincter.

Chronic constipation in patients with corrected Hirshsprung's disease is usually related to postoperative anal stenosis or residual aganglionosis. In our series we had 4 cases $(10 \%)$ of constipation postoperatively , one of them was due to aganglionosis and treated by reoperation, and one case had anal stricture which was treated by repeated dilatation.

\section{REFERENCES}

1) Langer JC (2004) : Persistent obstructed symptoms after surgery for Hirshsprung's disease : development of a diagnostic and therapeutic algorithm. J Ped. Surg.; 39: 1458-62.

2) Tomita R, Munakata , Howard ER, et al. (2004) : Histological studies on hirshsprung's disease and its allied disorders in childhood. Hepatogastro - entrology.; $51: 1042-4$

3) Kluck P, Tibboel D, Leendertse-Verloop AK, et al. (1986) : Diagnosis of congenital neurogenic abnormalities of the bowel with monoclonal antineurofilament antibodies. J. Ped. Surg.; 21:132-5.

4) EI Halaby AA, Hashish A,ELbarbary MM,et al. (2004) : Transanal one stage endorectal pull through for Hirshsprung's disease .A multicentral study. J . Ped. Surg.; 39: 345-51.

5) Polley TZ,Coran AG, Wesley JR (1985) : A 10 year experience with ninty- two cases of Hirshsprung's disease including 67 consecutive endorectal pull-through procedures. Ann. Surg.; 202: 349-55.

6) Bai Y,Chen $\mathrm{H}$, Hao J, et al. (2002) : Long-term outcome and quality of life after Swenson's procedure for Hirshsprung's disease. J. Ped. Surg.; 37:639-42.

7) Teielbum DH, Qualman SJ, Caniano DA (1988) : MANSOURA MEDICAL JOURNAL 
Hirshsprung's disease.

Identification of risk factors

for enterocolitis. Ann.

Surg.; 207: 240-4.

8) Wang's G,Yuan J, Zhou X, et al. (1996) : Modified operation for hirshsprung's disease : Posterior longitudinal anorectal split with a heart- shaped anastomosis. Ped. Surg. Int.; 11: 243-5.

9) Swenson 0 (2004) : Hirshsprung's disease a complicated therapeutic problem: Some thoughts and solutions based on data and personal experience over 56 years J. Ped. Surg.; 39 : 1449-53.

10) Teitelbaum DH,Coran AG (2003) : Reoperative surgery for Hirshsprung's disease. Semin. Ped. Surg.; 12:124-31.

11) Bagwall C, Langham MR, Mahaffey SM, et al. (1992) : Pseudomembranous colitis following resection for Hirshsprung's dis- ease. J. Ped. Surg.; 27 : 1261-4.

12) Blane $C A$,Elhalaby $A$, Coran AG (1994) : Enterocolitis following endorectal pullthrough in children with Hirshsprung's disease. Ped. Radiol.; 24:164-6.

13) Caniano DA, Teitelbaum DH, Qualman SJ (1990) : Mangment of hirshsprung's disease in children with trisomy. 21. Am. J. Surg.; $159:$ 402-4.

14) Elhalaby EA,Coran AG, Blane CE,et al. (1995) : Enterocolitis associated with Hirshsprung's disease: A clinical-radiological characterization based on 168 patients. J. Ped. Surg., 30:76-83.

15) Ikeda $K$ and Goto $S$ (1984) : Diagnosis and treatment of Hirshsprung's disease in Japan. Ann. Surg. 199; 400:

16) Jung PM (1995) : Hirshsprung's disease: One sur- 
gen experience in one institution.J.Ped.Surg.;30:646-

51.

17) Klein MD,Coran AG,Weslay JR,et al. (1984) : Hirshsprung's disease in the new born. J. Ped. Surg. 1984; 19:370.

18) Marty TL, Matlak MA, Handrickson $M$, et al. (1995) : Unexpected death from enterocolitis after surgery for Hirshsprung's disease. Pediatrics; 96: 118-21.

19 )Marty TL, Seo T, Sullivan JJ, et al. (1995) : Rectal irregations for the prevension of postoperative enterocolitis in Hirshsprung's disease. J. Ped. Surg.; 30 : 652-4.

20) Kleinhaus S,Boley SJ, Sheran M, et al. (1979) : Hirshsprung's disease : A survey of the members of the surgical resection of the American Academy of Pediatrics. J. Ped. Surg.; 14:58897.
21) Nixon HH (1985) : Hirshsprung's disease : Progress in management and diagnostics. World J. Surg.; 9:189-202.

22) Quinn FM,Surana $R$,Puri $P$ (1994) : The influence of trisomy 21 on outcome in children with Hirshsprung's disease. J. Ped. Surg.; 29:781-3.

23) Rescorla FJ, Morrison AM, Anglas D, et al. (1992) : Hirshsprung's disease :evaluation of mortality and long-term function in 260 cases. Arch. Surg.; 127: 934-42.

24) Sherman JO,Snyder ME, Weitzman JJ, et al. (1989) : A 40-year multinational retrospective study of 880 Swenson's procedures. J. Ped. Surg.; 24: 833-8.

25) Tarq GM,Brereton RJ, Wright VM (1991) : Complications of endorectal pull-through for Hirshsprung's disease. J. Ped. Surg., 26:1202-6.

MANSOURA MEDICAL JOURNAL 
24 SWENSON'S OPERATION FOR TREATMENT etc...

26) Kamal AE,Abdel Azim

A,Sabry M (2005) : Inter-

nal anal sphincter : Is it

properly managed during

27) Estevao -Costa J,Fragosa

resectional surgery for

gery.Vol.24,No.4,Oct.;

Hirshsprung's disease ?.

Egyptian Journal of Sur-

AC,Campas M, et al. : An approach to minimize postoperative enterocolitis in

Hirshsprung's disease 